\title{
Inadvertent Port: Catheter Placement in Azygos Vein
}

\author{
K. Harish, M.S., M.Ch., F.A.I.S., F.I.C.S. ${ }^{1} \quad$ Y. C. Madhu, M.S., M.Ch. ${ }^{1}$ \\ ${ }^{1}$ Department of Surgical Oncology, M S Ramaiah Curie Centre of \\ Oncology, M S Ramaiah Medical College, Bangalore, Karnataka, India \\ Address for correspondence and reprint requests K. Harish, M.S., \\ M.Ch., F.A.I.S., F.I.C.S., 2866, 13th Main 'E' Block, Subramanyanagar, \\ Bangalore 560010, Karnataka, India (e-mail: drkhari@yahoo.com).
} Int J Angiol 2012;21:103-106.

\begin{abstract}
Keywords

- catheter

- port

- azygos vein

- subclavian vein

Totally implantable ports are safe and effective means of venous access for administration of chemotherapy. One of the usual vessels accessed, through which the port is placed, is the subclavian. Herein, we report a case where the central access was obtained through the left subclavian vein. But the catheter when it was placed was found to be in the azygos vein. This was confirmed with dye study. This is the first report of such an occurrence with subclavian access. The catheter was later withdrawn and repositioned in the superior vena cava. We recommend that the entire procedure of catheter placement must be done under fluoroscopy guidance to ensure safe and error-free positioning.
\end{abstract}

Long-term venous access can be achieved with implantable ports. They are indicated for patient therapies requiring repeated venous accesses. These include infusion of medications as in cancer chemotherapy, intravenous fluids, parenteral nutritional support, blood products, and repeated blood sampling. Infection, suspected allergy to the device, and previous episodes of venous thrombosis are contraindications for port placement. The possible complications at port placement include air embolism, brachial plexus injury, pneumothorax, cardiac arrhythmia, and hematoma. Other complications include infection, skin erosion, catheter thrombosis or embolism, and perforation of vessel or viscera.

Totally implantable ports for chemotherapy administration are routinely done at our hospital for all patients. These are safe and effective means of venous access for administration of chemotherapy. ${ }^{1}$ The ports are usually placed in the subcutaneous pocket in the infraclavicular area in front of the chest wall. One of the accesses to central venous system is through the subclavian approach. The procedure involves a percutaneous guide wire (Seldinger) technique under local anesthesia.

\section{Case Report}

A 34-year-old woman was diagnosed to have right-sided locally advanced breast cancer for which neoadjuvant chemotherapy was planned. She was presented to us for chemo port placement which was planned to be placed on the left side. The left subclavian vein was punctured under local anesthesia from a lateral approach in the infraclavicular area to avoid "pinch off". ${ }^{2}$ The guide wire was inserted up to right atrium under fluoroscopy and the introducer needle was withdrawn. The vessel dilator and sheath introducer were advanced over the guide wire as a single unit and its position in the superior vena cava (SVC) was confirmed under fluoroscopy. The vessel dilator and guide wire were removed leaving the sheath in place. The catheter was introduced into the sheath and advanced. There was resistance at $23 \mathrm{~cm}$ marking. Fluoroscopy was performed to check the position. The catheter was found outside the cardiac shadow (-Fig. 1). Although misplacement was evident the exact location in the azygos vein was identified and confirmed by the dye study with iopromide (5-methoxyacetylamino-2,4,6-triiodisophthalicacid-(2,3-dihydroxy-N-methylpropyl)-(2,3-dihydroxypropyl)-diamide), in aqueous solution of $10 \mathrm{~mL}$ (-Fig. 2). The sheath and catheter was withdrawn under fluoroscopy guidance to subclavian vein and the catheter was advanced for placement in SVC atrial junction (-Fig. 3).

\section{Discussion}

As catheter is advanced in the sheath it enters the SVC, the right atrium, and the right ventricle or inferior vena cava. In 


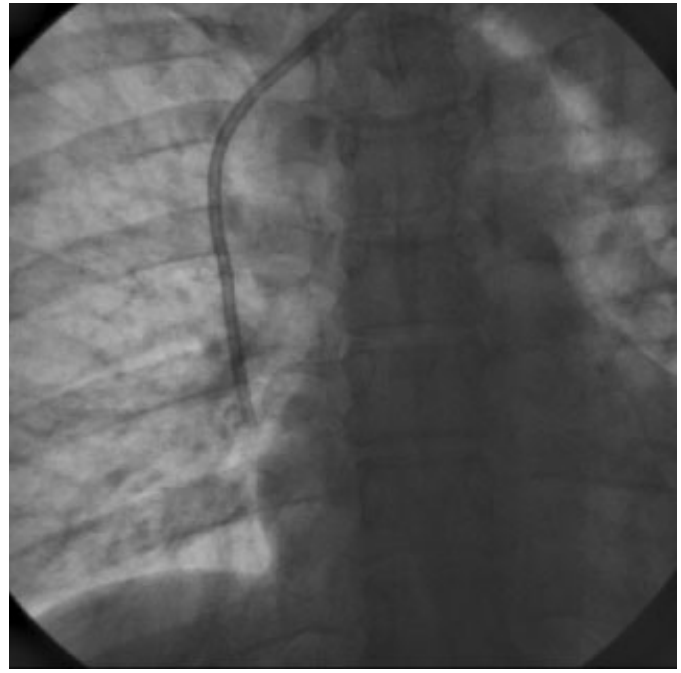

Figure 1 Fluoroscopy image showing catheter in the azygos vein. Note the position outside the cardiac silhouette.

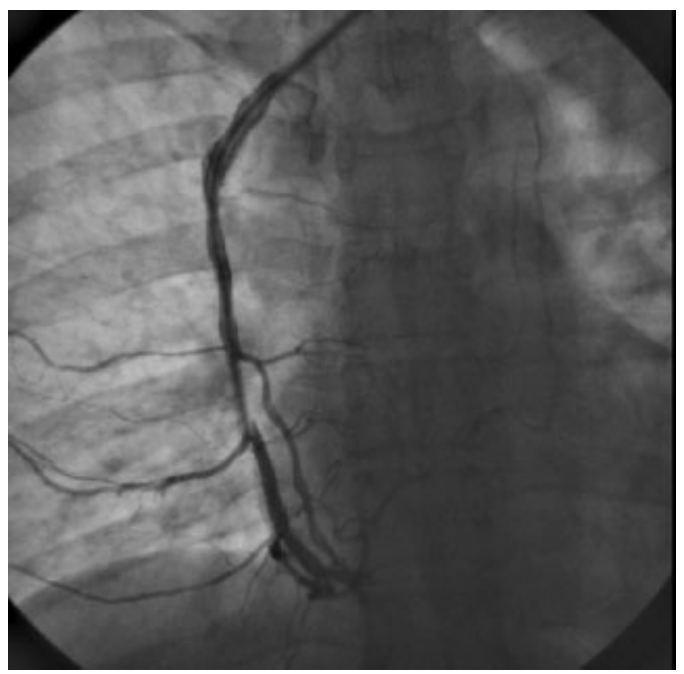

Figure 2 Image with intravenous contrast injected confirming the position of the catheter in the azygos with dye displaying many tributaries.

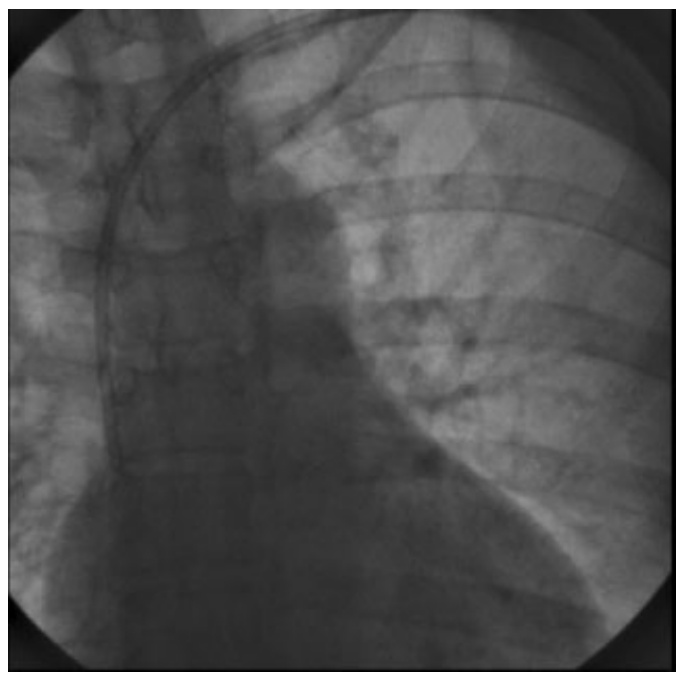

Figure 3 Image after repositioning of the catheter. this case, the catheter entered the azygos vein. Azygos vein joins the SVC after arching over the root of the right lung. The sheath tip is usually in the subclavian or upper part of SVC. Since the azygos vein joins the SVC posteriorly, it is unusual for the sheath tip to be at the ostium with either right or left subclavian access. This is because the vein ostium is not in the direction of advancement of sheath. However, in this case, the sheath tip must have been in the SVC at the ostium of the azygos vein probably because of a more lateral entry of the azygos vein into SVC. In addition, the sheath straightens a little when the introducer with guide wire is withdrawn. This could have contributed to the tip lodging itself or "stuck" into the ostium of the azygos vein. When the catheter was advanced into the sheath, the catheter entered the azygos vein. When the sheath with catheter was partially withdrawn, into subclavian vein and advanced again, the catheter entered SVC.

Totally implantable ports are used to administer chemotherapy. The placement of the tip is at the SVC-atrial junction. However tip could be placed in the SVC, atrium, or innominate veins. ${ }^{3}$ The entire procedure is done under fluoroscopic guidance in the cardiac intervention laboratory in our hospital since much of the procedure is similar to pacemaker insertion and the paramedics are conversant with the technique. In addition, there is ease of movement of C-arm and the operating table. The fluoroscopic visualization of the procedure is superior with "still" and "video" capture facility. Access to central vein has been recommended through subclavian or internal jugular veins. ${ }^{3}$ Rarely other veins including femoral veins have been used to access the central vein. ${ }^{4}$ Some nonrandomized studies have claimed higher incidence of venous thrombosis in left subclavian approach. ${ }^{5}$ At our center, for patients with breast cancer, the catheter is inserted in the contralateral side. Hence, left side was chosen for this case. In addition, in our experience, we have not found any increase in venous thrombosis in left subclavian access vis-avis the right. There is a debate of open versus percutaneous approach to subclavian puncture. ${ }^{5}$ However, the complication is unrelated to this.

The frequency of accidental azygos vein cannulation during a central venous access through internal jugular vein is $\sim 0.7$ to $1.2 \% .^{6,7}$ The smaller size of azygos (6 to $7 \mathrm{~mm}$ ) as against superior vena cava $(1.5-2 \mathrm{~cm})$ and opposite directions of blood flow contribute largely to the complications of azygos cannulation. ${ }^{8}$ Injury to the vessel is fraught with danger with perforations in azygos reported in up to $19 \%{ }^{8}$ In some circumstances like thrombosis of both superior and inferior vena cavae, azygos vein access is suggested as an alternate route for hemodialyis. ${ }^{9}$ That indication is irrelevant here as one of the main objectives of port is to dilute the chemotherapeutic drugs with large volume of blood on entry into the system. This objective is lost with azygos cannulation.

There is an argument for insertion of the catheter without guidance. ${ }^{10,11}$ However, in our own experience of 143 port placements through subclavian access, the guide wires have been found in contralateral subclavian vein, ipsilateral and contralateral internal jugular veins which were then repositioned. Sometimes the guide wire or the catheter is found to 
irritate the endocardium resulting in ectopic. Withdrawal and repositioning is best done under fluoroscopy. If catheter is not properly placed, all these objectives would be lost. To our knowledge, this is the first case where azygos vein has been catheterized inadvertently during chemo port catheter insertion.

In conclusion, we recommend that the entire procedure must be confirmed with fluoroscopy at the end of each step. During the entire procedure, one should be aware of malpositions into veins other than SVC including the azygos vein. This would ensure safe and proper placement of the catheter and avoid errors.

\section{References}

1 Barrios CH, Zuke JE, Blaes B, Hirsch JD, Lyss AP. Evaluation of an implantable venous access system in a general oncology population. Oncology 1992;49(6):474-478

2 Denny MA, Frank LR. Ventricular tachycardia secondary to Port-a-Cath fracture and embolization. J Emerg Med 2003;24(1): 29-34

3 Ignatov A, Hoffman O, Smith B, et al. An 11-year retrospective study of totally implanted central venous access ports: complica- tions and patient satisfaction. Eur J Surg Oncol 2009;35(3): 241-246

4 Bertoglio S, DiSomma C, Meszaros P, Gipponi M, Cafiero F, Percivale P. Long-term femoral vein central venous access in cancer patients. Eur J Surg Oncol 1996;22(2):162-165

5 Whitman ED. Complications associated with the use of central venous access devices. Curr Probl Surg 1996;33(4):309-378

6 Bankier AA, Mallek R, Wiesmayr MN, et al. Azygos arch cannulation by central venous catheters: radiographic detection of malposition and subsequent complications. J Thorac Imaging 1997; 12(1):64-69

7 Langston CS. The aberrant central venous catheter and its complications. Radiology 1971;100(1):55-59

8 Asudani D, Wretzel S, Patel R, Stayman A. A judgment call. Cleve Clin J Med 2008;75(10):690-691, 695

9 Meranze SG, Burke DR, Feurer ID, Mullen JL. Spontaneous retraction of indwelling catheters: previously unreported complications. JPEN J Parenter Enteral Nutr 1988;12(3):310-312

10 Kincaid EH, Davis PW, Chang MC, Fenstermaker JM, Pennell TC. "Blind" placement of long-term central venous access devices: report of 589 consecutive procedures. Am Surg 1999;65(6): 520-523, discussion 523-524

11 La Bella G, Kerlakian G, Muck P, Chung D, Vaughan A, Ritchison A. Port-A-Cath placement without the aid of fluoroscopy or localizing devices: a community hospital series. Cancer J 2005;11(2): 157-159 